\title{
VARIA
}

\section{NUEVAS OBRAS DE LUIS Y JOSÉ SALVADOR CARMONA ${ }^{1}$}

Hace unos años publicábamos un artículo sobre un grupo de esculturas de José Salvador Carmona aún existentes o procedentes del convento de San Miguel de las Victorias de la villa de Priego en la provincia de Cuenca ${ }^{2}$. Del conjunto existía una descripción del Padre Pedro Cruz Ocaña redactada antes de su dispersión ${ }^{3}$ y en el momento de realizar el trabajo nos encontramos con el hecho de que dos de las figuras del inventario no estaban en el pueblo y nada nos supieron decir sobre su paradero.

En una visita a la Catedral de Cuenca tuvimos la sorpresa de encontrarlas en las dependencias del muses catedralicio. Las esculturas localizadas ahora son un San Pascual Bailón y un San Francisco de Asís recibiendo los estigmas. El primero de ellos, mide aproximadamente 0,85 ms., muestra al santo a la manera habitual en él, en pie, en acusado contraposto, vestido con el hábito y la capa franciscana y los brazos abiertos, en uno de los cuales porta una custodia, hoy desaparecida, a la que dirige la mirada, y el otro extendido en un gesto instintivo de emoción. La cabeza, sin llegar al realismo o a la concentración de las obras del tío, resulta expresiva y de un acusado anhelo. Al grato efecto de la figura ayuda la calidad de la policromía del hábito. Su dependencia del conocido San Pascual de la iglesia de San Miguel de Madrid, obra del tío Luis Salvador Carmona, es evidente y al mismo tiempo, muestra las diferencias, talla más apurada y rostro más realista y expresivo en la efigie madrileña ${ }^{4}$. Según el inventario del Padre Cruz Ocaña, la escultura formaba pareja, en un altar del presbiterio, con un San Benito de Palermo, hoy en la parroquial de Priego. Ambas tienen idéntica postura pero contrapuesta, buscando un efecto de simetría.

Publicamos cómo a la iglesia del convento de San Miguel se abría una capilla titulada «de la Impresión de las Llagas», y a ella pertenecía el hermoso Cristo alado conservado también en la parroquial, pero no apareció por sitio alguno un San Francisco que pudiera completar la escena. La escultura también se conserva en la Catedral de Cuenca y ya fue publicada con atribución a Luis Salvador Carmona en la Guía de la Catedral de Jesús Bermejo Díez ${ }^{5}$. La obra muestra al Santo con una de sus rodillas hincada en tierra, los brazos abiertos con las palmas

\footnotetext{
1 Este trabajo forma parte de un proyecto de investigación financiado por la DGES (PB98-0708).

2 Nicolau Castro, Juan: «Las esculturas de José Salvador Carmona del convento de San Miguel de las Victorias de Priego (Cuenca)», Boletín del Seminario de Estudios de Arte y Arqueología, T.LIX, 1993, pp. 455-464.

${ }^{3}$ Cruz Ocaña, Pedro: El Convento de San Miguel de las Victorias de Priego, Imprenta Seminario Conciliar, Cuenca, 1929.

${ }^{4}$ Garcia Gainza, Concepción: El escultor Luis Salvador Carmona, Universidad de Navarra, 1990 y Martin González, Juan José: Luis Salvador Carmona. Escultor y Académico, Ed. Alpuerto, Madrid, 1990.

${ }^{5}$ Bermejo Diez, Jesús: La Catedral de Cuenca, Caja de Ahorros de Cuen ca, 1977.
} 
de las manos hacia el frente y el rostra fijo en el Crucifíjo, en anhelante éxtasis. Por lo demás, su talla sumaria es la repetida una y otra vez par José Salvador Carmona. Desgraciadamente nos ha llegado con uno de sus ojos de cristal roto y en estos momentos se encuentra en proceso de restauración ${ }^{6}$.

Varias de las esculturas de Priego se expusieron en 1956 en una magna exposición de arte sacro en el Museo de Cuenca, el catálogo fue encargado a Don Diego Angulo que contó con la colaboración de Carmen Bernis y de Jesús Hernández Perera y en él, con gran sutileza, se atribuye el San Pascual Bailón «a la escuela» de Luis Salvador Carmona y nada se dice del San Francisco, ya que, dado su deterioro, no debió exhibirse ${ }^{7}$.

Procedentes de otro convento franciscano, hoy desaparecido, el de Ntra. Sra. del Rosario, conocido vulgarmente como del Rosarito, ubicado en una de las márgenes del rio Tiétar, en el término de la toledana villa de Oropesa, se conserva otro conjunto de esculturas de santos franciscanos, en la parroquia de Ntra. Sra. de la Asunción de esta villa, atribuibles también al taller de José Salvador Carmona ${ }^{8}$.

El convento del Rosarito se funda en 1557 a instancias de San Pedro de Alcántara bajo el patrocinio del III Conde de Oropesa, Don Fernando Álvarez de Toledo. En el siglo XVIII, al parecer, hubo un resurgir bajo el patrocinio de Don Julián Pascueña, obispo de Avila ${ }^{9}$. Suponemos que, tras la desamortización del XIX, el monasterio fue abandonado, quedando reducido a la ruina actual en medio del idilico paisaje con el telón de fondo de las cumbres de Gredos.

Sobre él hemos localizado algunos datos documentales inéditos que efectivamente nos apuntan a una importante actividad constructiva a lo largo del siglo XVIII. Por ellos sabemos que en 1729 se hace un nuevo camarín a la Virgen del Rosario. En 1748 se erige un nuevo edificio para la enfermería que el convento poseía en Oropesa y se consiguen en Madrid «los diseños y el plano de Don Ventura Rodríguez Arquitecto de S. magd». De 1750 es una nota en la que se da cuenta de como se colocaron ese año «las imágenes de la Concepción y el Santo Negro (sic) que están en la capilla mayor». En 1777 se dan por terminadas una serie de importantes obras que reforman, en gran parte, la iglesia. Finalmente, contamos con una última noticia interesante en la que se nos informa de la procedencia madrileña del sagrario-tabernáculo y gradería del retablo que llegaban de la Corte en 1786, lo que apunta a la vinculación madrileña del convento, como ya hemos visto, con la participación de Don Ventura Rodríguez ${ }^{10}$.

Las esculturas procedentes de allí que hemos localizado, al margen de la imagen de la Virgen titular, figura de vestir también del siglo XVIII, se reducen a cuatro santos franciscanos, San Francisco, San Antonio, San Benito de Palermo y San Pascual Bailón, y al dominico San Pedro mártir.

El San Francisco, mide 1,10 ms., se encuentra groseramente repintado y ha perdido ambas manos sustituidas par unas modernas de burda tosquedad. En unà de ellas portaría un Crucifijo, como puede verse en el Santo del mismo escultor del cercano monasterio de Arenas de San Pedro, al que dirigía la mirada y la otra quedaría simplemente abierta en actitud de súplica,

\footnotetext{
${ }^{6}$ Deseo agradecer al 11 mo.Sr. D. Santos Saiz Gómez, Dean del Ilmo.Cabildo Catedral de Cuenca, la amable colaboración prestada para el estudio de estas obras.

7 Angulo Iñiguez, Diego, Bernis Madrazo, Carmen y Hernández Perera, Jesús: Exposición de Arte Antiguo. Museo de Cuenca, Cuenca, 1956.

${ }^{8}$ Debo el conocimiento de este conjunto de esculturas y su lugar de procedencia al Padre Victorino Terradillos, del Convento Franciscano de la Puebla de Montalbán, quien amablemente me ha ayudado en todas mis investigaciones en conventos de su Orden.

9 Garcia Gil, Octavio y Fernández Arroyo, Andrés: Oropesa. Señorío y Condado, Ayuntamiento de Oropesa y Diputación Provincial de Toledo, 1997.

${ }^{10}$ Archivo Franciscano Ibero-Oriental: Papeles del Monasterio de Ntra. Sra. del Rosario entregados en 1903 por D. Luis Jimenez de la Llave, fols. 17 a 45
}

AEA, LXXV, 2002, 300, pp. 407 a 446 

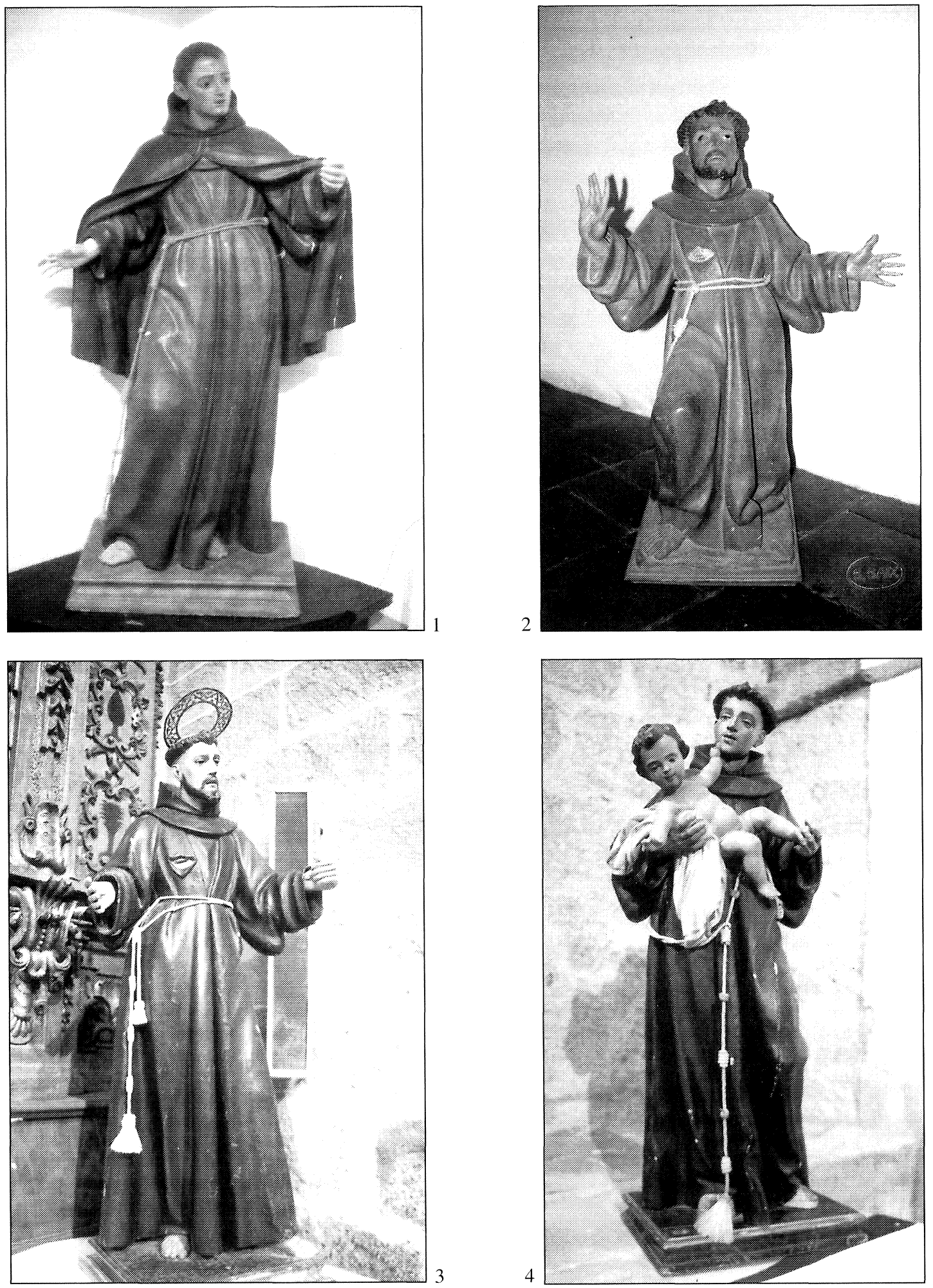

Fig. 1. José Salvador Carmona, San Pascual Bailón. Catedral de Cuenca.

Fig. 2. José Salvador Carmona, San Francisco en éxtasis. Catedral de Cuenca.

Fig. 3. José Salvador Carmona, San Francisco de Asís. Paroquia de Oropesa (Toledo).

Fig. 4. José Salvador Carmona, San Antonio de Padua. Parroquia de Oropesa (Toledo).

AEA, LXXV, 2002, 300, pp. 407 a 446. 
mostrando la huella de su llaga. Separan esta versión de las de Priego y Arenas de San Pedro el que éstas apoyan un pie sobre el globo terráqueo mostrando su desprecio del mundo, ello hace que los pliegues del hábito del de Oropesa, casi idénticos en la zona del pecho, se simplifiquen hasta el extremo en su caida desde la cintura. Es curioso observar hasta que punto se seguían recetas en el taller, comparando el desgarrón del hábito que muestra la llaga del costado idéntico en las versiones conocidas. Por lo demás, la tosca policromía se ha llevado primores de talla en cabellos y cabeza que aquí sólo se insinúan y que llegan a un gran virtuosismo en el ejemplar del monasterio abulense ${ }^{11}$.

Algo parecido ocurre con el San Antonio de Padua, que mide 0,90.ms, y aparece también groseramente repintado. Pero a pesar de ello es figura mucho más grata. Porta en sus brazos, cogido con un paño blanco, al Niño Jesús gracioso y juguetón, que mira, no al Santo, sino al espectador que está bajo sus pies. El Santo de rostro vivo, exento de distinción, como surgido del pueblo llano, tampoco mira al Niño, sino que eleva su mirada por encima de él. La comparación con el San Antonio de Priego muestra que nos encontramos ante dos figuras casi gemelas, aunque el conquense tiene un rostro menos expresivo y la figura del Niño parece tallada de manera exenta. Desgracidamante, la tosca policromía del hábito resta mucho de su belleza a la talla.

En uno de los pilares del crucero se ha colocado otra figura, sin duda procedente del mismo convento, aunque su excesiva altura nos ha impedido una observación cuidadosa de la ta1la. Se trata de San Benito de Palermo, santo bastante popular a lo largo del siglo XVIII, a juzgar por la abundancia de su iconografía. E1 escultor también integró esta imagen en el conjunto de Priego, pero ésta conservada en Oropesa es más movida, tiene más vida y un mayor realismo en sus rasgos raciales. La actitud, sin embargo, es la misma, con los brazos abiertos en cuyas manos portaría un Crucifijo y un corazón llameante. El deterioro de la figura, aunque no parece haberse repintado, es muy grande y ha perdido una de las manos, mientras la otra mutilada se ve desencajada del brazo. Ante esta figura, con un tratamiento más movido y realista de paños y sobre todo con un rostro de rasgos negros, tomado de la realidad, mucho más veraz que la figura de Priego, nos viene la duda, partiendo de la fecha documental con que contamos de la colocación en 1750 «del Santo Negro», de si la imagen podría pertenecer al tío que por esas fechas, con 42 años de edad, estaba en momento clave de su producción. Quede ello, de momento, como una simple hipótesis, que sólo documentos más precisos o la contemplación cercana de la talla podría desvelar ${ }^{12}$.

E1 cuarto santo franciscano es un San Pascual Bailón que mide 0,80 ms. La escultura, aunque deteriorada, nos ha llegado sin retoques habiendo perdido la custodia y teniendo mutilados algunos de los dedos de las manos. Repite casi al pie de la letra el San Pascual de Priego, hoy en la catedral conquense, en todo menos en la cabeza. La cabeza del santo de Priego es más idealizada y muestra un gesto ensimismado, la de Oropesa es más realista, menos fina de talla, pero más llena de humanidad.

Por último, forma parte del conjunto una talla del dominico San Pedro Mártir, imagen muy bella, muy en la línea del mundo rococó y que, a pesar de haber perdido ambas manos, ha llegado en relativo buen estado. E1 hábito dominico se mueve acompasadamente en un hermoso ritmo de curvas y contracurvas. Su rostro en éxtasis, mirando al cielo, resulta hermoso y convincente. Ha perdido la espada o cuchillo que le taladraba el cráneo, pero conserva la sangre que cae par el cuello y mancha la capucha del hábito, y, como dato curioso, lleva colgada al

\footnotetext{
1 Nicolau Castro, Juan: «En torno a Luis Salvador Carmona y la escultura de su tiempo», B.S.A.A., T.LVI, 1990, pp. $562-568$.

12 Otro San Benito de Palermo que puede relacionarse también con el estilo de José Salvador Carmona es el conservado en el Convento Franciscano de Pastrana, Alli se conserva también un San Pedro de Alcántara atribuible al mismo circulo.
}

$A E A, \mathrm{LXXV}, 2002,300$, pp. 407 a 446 

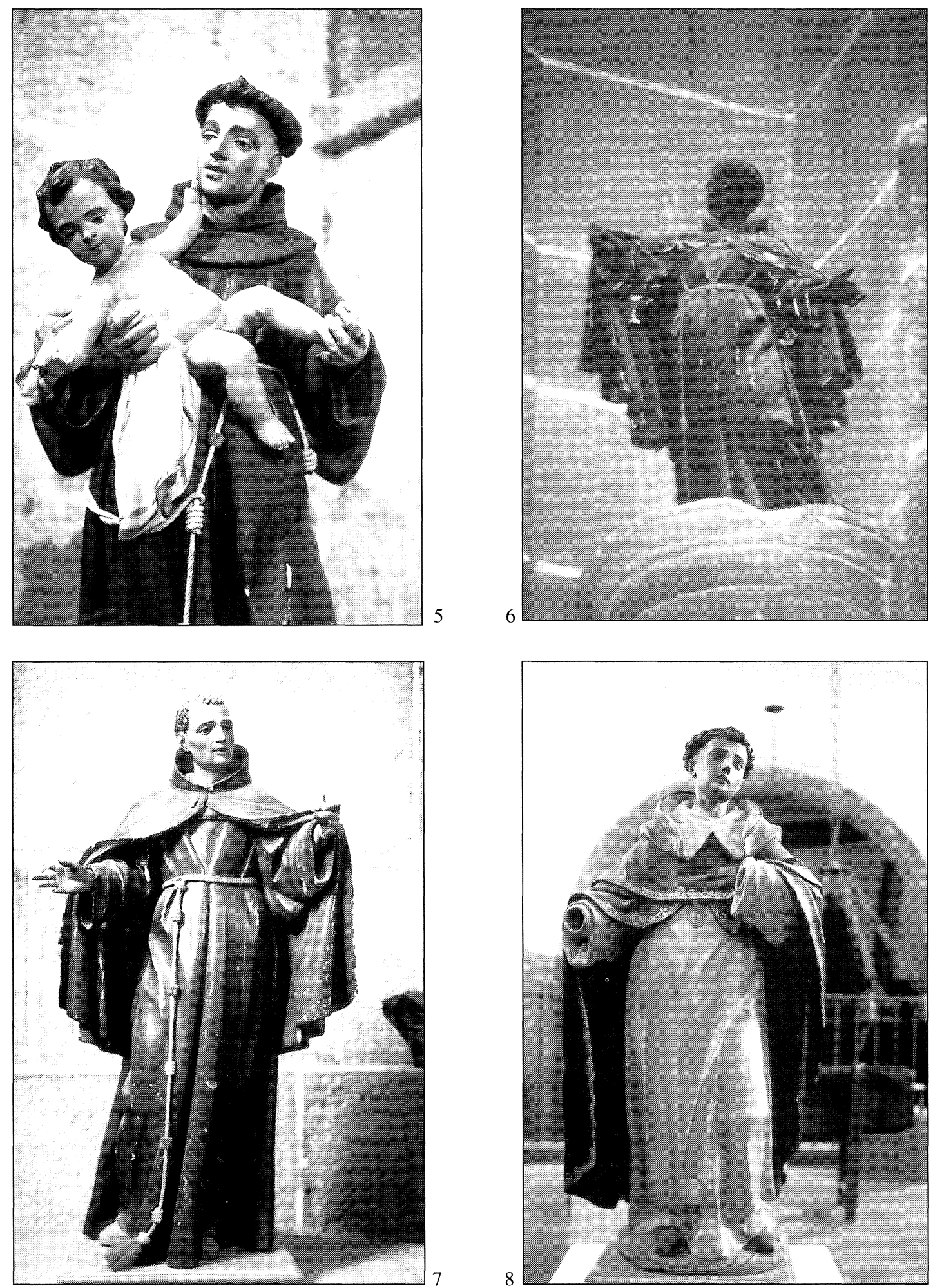

Fig. 5. José Salvador Carmona, San Antonio de Padua (detalle).

Fig. 6. José Salvador Carmona (?), San Benito de Palermo. Parroquia de Oropesa (Toledo).

Fig. 7. José Salvador Carmona, San Pascual Bailón. Parroquia de Oropesa (Toledo).

Fig. 8. José Salvador Carmona, San Pedro Mártir. Parroquia de Oropesa (Toledo).

AEA, LXXV, 2002, 300, pp. 407 a 446 
cuello y resurge en la cintura una medalla pintada con el escudo de la Inquisición. Todos los bordes del hábito están orlados de una fina greca dorada. Posiblemente debi6 existir en el conjunto algún otro santo dominico que o bien no nos ha llegado o se encuentra ubicado en algún lugar alto o perdido de la parroquia.

Al margen de estas esculturas de indudable autoría carmonesca, se conserva también en Oropesa otra deteriorada imagen de San Bartolomé con el diablo a sus pies que muestra también en su talla caracteres similares, como en el tratamiento del barbado rostro, en la policromia, en la manera de atar el ceñidor a la cintura o en la terminación en sinuoso pico del cuello de la túnica.

Resulta por lo demás interesante la existencia de estos conjuntos de escultura salidos del taller de José Salvador Carmona en conventos franciscanos, que experimentan una intensa actividad constructiva en la segunda mitad del siglo xvIII y en la que parece intervienen personas vinculadas con la Corte o con la propia persona del Rey.

Y una nueva obra de Luis Salvador Carmona creemos poder añadir a su extenso catálogo. Se trata de una bellísima Virgen, con el título de Ntra. Sra. de la Asistencia, que, procedente de la iglesia del Hospital de San Andrés de los Flamencos, se guarda hoy en el Monasterio de Sta. Maria da la Cruz, o de Santa Juana, de Cubas de la Sagra donde permanecen en depósito la mayor parte de los objetos de culto de San Andrés, cuando esta Institución se renovó y se constituyó en la actual Fundación «Carlos de Amberes». Debido a la reciente publicación sobre esta benéfica Institución de la obra de las Dras. Florentina y Benicia Vidal Galache, hoy conocemos todas las vicisitudes del Hospital de los Flamencos ${ }^{13}$ del que eran muy escasas las referencias existentes con anterioridad. Ponz sólo hace una brevísima referencia al cuadro de Rubens que presidía el altar de la iglesia ${ }^{14}$ y Tormo ni siquiera nombra el edificio, sólo poseíamos breves noticias documentales aportadas por la Dra. Virginia Tovar, según las cuales, el antiguo edificio del Hospital se comienza en 1660 siguiendo trazas del Maestro Juan Ruiz y en él se entierra el gran arquitecto Pedro de la Torre en 1677 «debajo de la tarima del altar de Nuestra Señora de los Aflijidos» ${ }^{15}$.

E1 Hospital de San Andrés de los Flamencos arranca del legado fundacional del flamenco Carlos de Amberes, se ubicaba primitivamente en la calle de San Marcos, en el barrio del Barquillo, y su primera iglesia, comenzada en 1621, se realizó siguiendo trazas de Juan Gómez de Mora. De las piezas artísticas conservadas en la iglesia ninguna tuvo la importancia de la pintura del martirio de San Andrés, de Rubens, que presidía el retablo mayor y que, de modo casi milagroso, sigue presidiendo actualmente la renovada Institución. Allí, a la vuelta de la Corte de Valladolid, se instaló y funcionó la Cofradía de San Andrés de los Arqueros Reales hasta su extinción en 1683 y su sustitución por la Congregación de Ntra. Sra. de la Asistencia, patrona de las parturientas, que encargaba una nueva imagen de este titulo en 1685 que no nos ha llegado y que estuvo situada en el presbiterio de la vieja iglesia. Después de innumerables vicisitudes, en 1876 se construyó una nueva Iglesia y Hospital en la zona de ensanche de Madrid, calle de Claudio Coello, donde aun permanece, obra de los arquitectos Agustín y Manuel Ortiz de Villajos. Allí se instalaría en 1879 la nueva Congregación de Ntra. Sra. de la Asistencia, «integrada exclusivamente par señoras». La devoción a ésta Virgen, especial protectora de parteras y la infancia, fue importante en Madrid, como podemos ver aun por viejas estampas guardadas en el archivo de la Fundación. Sus fiestas principales se celebraban en el mes de enero,

\footnotetext{
13 Vidal Galache, Florentina y Benicia: Historia del Hospital de San Andrés de los Flamencos. 1594-1994, Fundación Carlos de Amberes,1996, Ed. Nerea S.A.

14 Ponz, Antonio: Viage de España, T.V, Madrid,1793, pág. 243.

15 Tovar Martín, Virginia: Arquitectos madrileños de la segunda mitad del siglo XVII. Madrid, Instituto de Estudios Madrileños, 1975.
}

AEA, LXXV, 2002, 300, pp. 407 a 446 
el segundo domingo después de Epifania, el 2 de febrero, dia de la Purificación, y el dos de julio, dia de la Visitación. Además los sábados, a la una de la tarde, se celebraba misa de purificación de las madres que hubiesen dado a luz con la presentación de sus hijos a la Virgen ${ }^{16}$.

Al margen de esta larga aportación de datos y sin contar desgraciadamente con un documento que nos garantice una autoría y fecha contundente, opinamos que nos encontramos aquí con una bellísima obra de Carmona, llena del candor y del encanto que él supo imprimir a sus mejores Vírgenes. De pie, mide 1,30 ms., en elegante contraposto, se alza sobre un suelo rocoso apenas insinuado. Viste túnica roja y manto azul caido por la espalda, recogido artificiosamente con los brazos. Cubre la cabeza un velo blanco, colocado con sencillez y gracia que cae en pico sobre el hombro izquierdo del modo habitual en Carmona, mostrando su pelo oscuro solo hasta las orejas. Sus facciones, deliciosamente amuñecadas, son las repetidas una y otra vez por el escultor en sus más bellas mujeres, óvalo de la cara muy redondeado, con li-

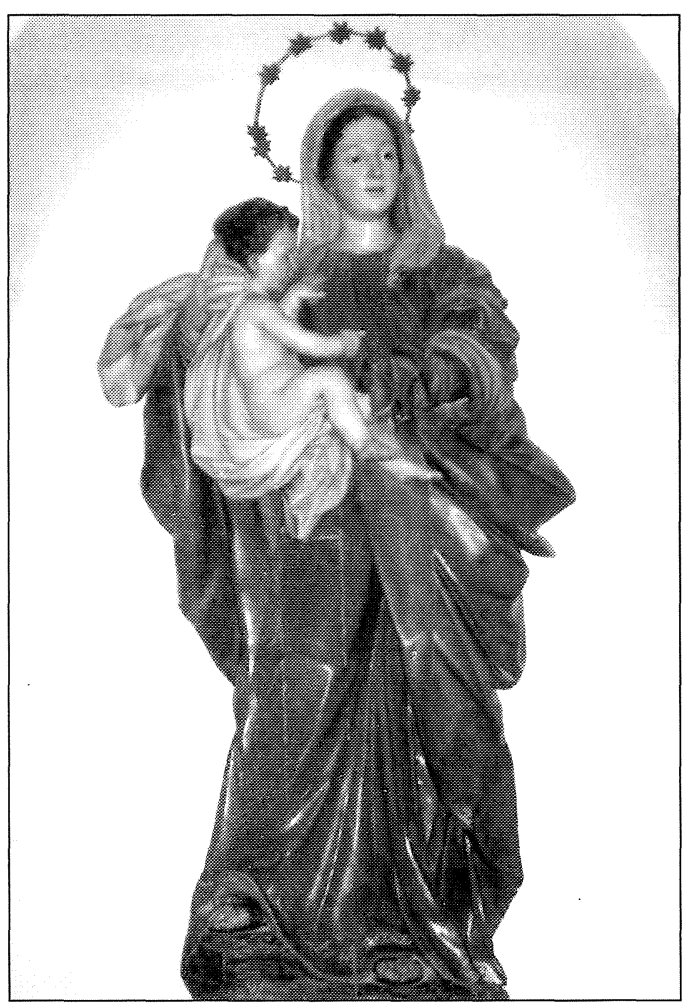

Fig. 9. Luis Salvador Carmona: Nuestra Señora de la Asistencia. Monasterio de Santa Juana. Cubas de la Sagra (Madrid). gera papada, cejas arqueadas, ojos más bien pequeños, nariz larga y boca de labios carnosos y casi diminuta. Sobre sus manos, envuelto en amplio paño blanco, porta un hermoso Niño en postura un tanto forzada, en la que muestra el protagonismo que tiene en la imagen y recuerda a un recien nacido al ser llevado al baño tras el parto. Las miradas no se cruzan, pues la madre tiene puestos los ojos en un lateral como buscando la mirada de los fieles. De las numerosas imánenes conocidas de Carmona la que más nos parece acercarse a ésta que damos a conocer, es la desaparecida Virgen del Rosario de San Fermín de los Navarros que se contrata en $1747^{17}$. Su rostro de idéntico óvalo y lleno del mismo encanto las acerca, si bien ésta de los Flamencos, al tener el cabello recogido, se aleja en parte de las formas más conocidas del escultor. E1 Niño, de formas muy realistas, con su original forma de ser llevado, creemos que es único en la producción de Carmona.

Hemos localizado también algunas noticias sobre otra imagen de la Virgen con la advocaci6n del Buen Parto, que pudiera estar relacionada con ésta, venerada en la iglesia de San Luis y que desapareció en 1935. Tormo, con su laconismo habitual decia de ella, «la imagen de la Virgen del Buen Parto es ya del siglo xviII, excelente» ${ }^{18}$, pero en otra curiosa publicación del Dr. Castillo de Lucas, estudioso de la Historia de la medicina ${ }^{19}$ se nos dice que fue

${ }_{16}$ Todos los datos sobre el Hospital de San Andrés de los Flamencos están tomados de la obra reseñada de las hermanas Vidal Galache y de la información directa que amablemente nos ha aportado la directora de la Institución, Sra. Catherine Geens, a quien agradecemos encarecidamente su amabilidad.

${ }_{17}$ Garcia Gainza, Concepción: Luis Salvador Carmona en San Fermín de los Navarros. Real Congregación de San Fermín de los Navarros, 1990.

18 Tormo, Elías: Las iglesias del antiguo Madrid. Instituto de España, Madrid, 1972.

${ }^{19}$ Castillo de Lucas, Antonio: «Devociones populares tocoginecológicas. Santos sanadores», Práctica médico-Quirúrgica Internacional, $1^{\circ}$ Trimestre, 1964, págs. 16-25. 
imagen muy popular en Madrid esta Virgen del Buen Parto del escultor Salvador Carmona, pero nada, ni siquiera una vieja fotografia, hemos hallado que nos ponga sobre una posible pista de la imagen.

Juan Nicolau Castro

Doctor por la Universidad Autónoma

\section{CONSIDERACIONES SOBRE PINTURA EN TIERRA DE CAMPOS: NUEVAS ATRIBUCIONES A LOS MAESTROS DE ASTORGA Y DE BECERRIL}

La pintura castellano-leonesa del siglo XVI comprende un vasto territorio que dificulta el conocimiento total de la misma, necesario para establecer conexiones entre las distintas escuelas; si a este hecho unimos la falta en mucho casos de la documentación proveniente de los libros de fábrica, el paisaje se complica. Hay que agradecer a todos los estudiosos que nos precedieron el haber dado a conocer la mayoría de las obras cuya autoría es aún hoy objeto de discusión. En este artículo no se pretende presentar nuevas teorías, sino que con la ventaja de más puntos de referencia, aunque se carece de la documentación pertinente en las dos obras tratadas, estilísticamente podemos aportar nuevas atribuciones que ayudarán a matizar más el panorama planteado.

En la parroquia de Santa María del Castillo en Torremormojón (Palencia) ${ }^{1}$ se encuentra un retablo cuyo cuerpo está formado por tres tablas (fig. 1), la central con la Virgen con el Niño y un donante, a su derecha San Juan Evangelista y a su izquierda San Nicolás; consta también de un banco con otras cinco tablas: San Pedro, San Miguel matando al demonio, Piedad, San Juan Bautista y la Visión de San Bernardo. Estas pinturas han sido tradicionalmente asignadas al Maestro de Calzada, personalidad estilística del primer renacimiento palentino creada por Post ${ }^{2}$, el primero en establecer esta atribución ${ }^{3}$. Este maestro se caracteriza por su formación hispanoflamenca, probablemente en el taller del Maestro Alejo, a la que se añaden fórmulas aprendidas de Pedro Berruguete sobre todo, pero también de Juan de Flandes. Su actividad se sitúa desde los inicios del siglo Xvı hasta el final de la década de los veinte ${ }^{4}$. Algunos investigadores se han desmarcado de la adscripción del retablo de Torremormojón al Maestro de Calzada, pero no han formulado otra autoría ${ }^{5}$. En la pintura palentina de las primeras décadas del siglo Xvi confluye el influjo de los dos pintores citados más arriba, Berruguete y Flandes; dependiendo del seguidor al que nos refiramos, el influjo de uno o de otro artista se hallará más pronunciado, pero al converger las influencias, en muchos casos es difícil discernir paternidades. Desconocemos en la mayoría de los casos los nombres de los pintores de esta épo-

\footnotetext{
' Existen, además de este retablo, dos tablas con Santa Catalina y Santa Lucía de cuerpo entero que no incluimos en nuestro análisis ya que, aunque se trata de pinturas contemporáneas al retablo, son de diferente autoría.

${ }^{2}$ Post, Raymond Chandler: A History of Spanish Painting, vol IX.I, 1947, pp 488-502.

${ }^{3}$ Con anterioridad, había sido atribuido a Juan de Flandes por Navarro García, Rafael: Catálogo Monumental de Palencia, t. IV, 1946 , p. 90 . Sancho Campo sigue parcialmente esta atribución, ya que en el tomo III de El Arte Sacro en Palencia, 1972, lams. 74 y 75 lo vincula al taller de Juan de Flandes.

${ }^{4}$ Silva Maroto, Pilar: «En torno a la pintura del primer tercio del siglo xvi en Palencia: el Maestro de Calzada» Anales de Historia del Arte, nº 6, 1996, pp. 163-189.

${ }^{5}$ Angulo Íñiguez, Diego: Pintura del Renacimiento. Ars Hispaniae, vol. XII, 1954, p. 105, equivoca el nombre de la localidad, al llamarla «Mormojón», le parece uno de los maestros más interesantes del momento; Silva Maroto, Pilar: $O p$ cit. , p. 174; Bermejo, Elisa: Catálogo de Las Edades del Hombre. Memorias y esplendores, Palencia, 1999, pp. 88-90, $\mathrm{n}^{\circ} 19$, considera que la obra del Maestro de Calzada es de inferior calidad.
}

$A E A, \mathrm{LXXV}, 2002,300$, pp. 407 a 446 